\title{
Optimizing the Definition of a Sudden Stratospheric Warming $\mathscr{O}$
}

\author{
AMY H. BUTLER \\ Cooperative Institute for Research in Environmental Sciences, University of Colorado Boulder, \\ and Chemical Sciences Division, National Oceanic and Atmospheric Administration/Earth \\ System Research Laboratory, Boulder, Colorado \\ EDWIN P. GERBER \\ Courant Institute of Mathematical Sciences, New York University, \\ New York, New York
}

(Manuscript received 27 September 2017, in final form 22 December 2017)

\begin{abstract}
Various criteria exist for determining the occurrence of a major sudden stratospheric warming (SSW), but the most common is based on the reversal of the climatological westerly zonal-mean zonal winds at $60^{\circ}$ latitude and $10 \mathrm{hPa}$ in the winter stratosphere. This definition was established at a time when observations of the stratosphere were sparse. Given greater access to data in the satellite era, a systematic analysis of the optimal parameters of latitude, altitude, and threshold for the wind reversal is now possible. Here, the frequency of SSWs, the strength of the wave forcing associated with the events, changes in stratospheric temperature and zonal winds, and surface impacts are examined as a function of the stratospheric wind reversal parameters. The results provide a methodical assessment of how to best define a standard metric for major SSWs. While the continuum nature of stratospheric variability makes it difficult to identify a decisively optimal threshold, there is a relatively narrow envelope of thresholds that work well—and the original focus at $60^{\circ}$ latitude and $10 \mathrm{hPa}$ lies within this window.
\end{abstract}

\section{Introduction}

In the decades following the first observations of a major sudden stratospheric warming (SSW) by Scherhag (1952), various metrics were developed to classify extreme events in the stratosphere (Butler et al. 2015). During an SSW, the winter stratosphere rapidly warms and the climatological westerly polar vortex decelerates, often reversing entirely. Thus the earliest SSW definitions adopted by the World Meteorological Organization (WMO) focused on temperature gradient and zonal wind reversals at the $10-\mathrm{hPa}$ pressure level $(\sim 30 \mathrm{~km})$, and poleward of $60^{\circ}$ latitude (WMO/IQSY 1964; Quiroz et al. 1975; WMO CAS 1978, p. 36, item 9.4.4; McInturff 1978; Labitzke 1981). The initial focus on $10 \mathrm{hPa}$ and

Supplemental information related to this paper is available at the Journals Online website: http://dx.doi.org/10.1175/JCLID-17-0648.s1.

Corresponding author: Amy Butler, amy.butler@noaa.gov $60^{\circ} \mathrm{N}$ arose from careful synoptic analysis of where the greatest changes were being observed during these events (WMO/IQSY 1964). It was also likely informed by the availability of data; most of the earliest observations were taken by radiosondes and rocketsondes equatorward of $60^{\circ} \mathrm{N}$ over Northern Hemisphere (NH) midlatitude land regions (Oort and Liu 1993). Today the most commonly used definition for SSWs still relies on the zonal-mean zonal wind reversal at $60^{\circ}$ latitude and $10 \mathrm{hPa}$ (Charlton and Polvani 2007).

Recent work has shown, however, that the classification of major SSWs by this simple zonal wind definition is sensitive to the choice of latitude, pressure level, and threshold used to detect the events (Butler et al. 2015; Palmeiro et al. 2015). Various other techniques, including annular modes (Baldwin 2001; Baldwin and Thompson 2009; Gerber et al. 2010), geometric vortex diagnostics (Waugh and Randel 1999; Hannachi et al. 2011; Mitchell et al. 2011; Seviour et al. 2013), deceleration-based measures (Kim et al. 2017), temperature changes (Blume et al. 2012; Maury et al. 2016), and empirical orthogonal 
functions (EOFs) (Hitchcock et al. 2013) have also been used to detect extreme polar vortex events. These too ultimately rely on arbitrary thresholds, are sensitive to the parameters chosen, and can be more computationally intensive.

Given the sizable increase in measurements of the middle atmosphere since the satellite-era began, we conduct a systematic evaluation of where a zonal wind reversal should be defined in order to "optimize" the classification of major SSWs. The detection algorithm should, first and foremost, isolate events that are 1) sudden, involving a rapid deceleration of the stratospheric polar vortex, and 2) warming, with a largeamplitude temperature increase. Ideally, the definition will also capture events with significant two-way coupling between the troposphere and stratosphere, maximizing 3) the upward wave propagation into the stratosphere prior to events and 4) the downward coupling of the zonal mean circulation to the surface after events. After presenting our methodology in section 2, we consider how the frequency of events changes in relation to pressure level, latitude, and threshold of the zonal wind deceleration and show where criteria 1-4 above are optimized in relation to these parameters in section 3. Our conclusions are presented in section 4.

\section{Methodology}

We use daily-mean output of JRA-55 from 1958 to 2016 (Ebita et al. 2011), but the results are robust to the choice of reanalysis. Daily anomalies are calculated relative to a smooth annual cycle, computed by averaging each calendar day over the entire period, and then filtering in Fourier space by retaining only the first four harmonics. For the Arctic Oscillation (AO) index, we use daily historical values provided by the National Centers for Environmental Prediction (NCEP) Climate Prediction Center (CPC), which are based on EOF analysis of the 1000-hPa geopotential height anomalies from the NCEP-NCAR reanalysis data and standardized by the December-March (DJFM) daily values.

A commonly used definition for major midwinter SSWs is a reversal of the zonal-mean zonal winds at $60^{\circ} \mathrm{N}$ and $10 \mathrm{hPa}$ during the months of November-March (Charlton and Polvani 2007, hereafter CP07). CP07 require that reversals be separated by at least 20 consecutive days of westerlies to ensure events are independent, and that westerlies must return for at least 10 consecutive days prior to 30 April to avoid including final warmings. Disadvantages of this definition are that, by construction, it does not detect final warmings, and the 30 April requirement is an arbitrary cutoff. We address these with minor changes to the CP07 method.
We extend the analysis from 1 July to 30 June of the following year, and first detect the start and end of the vortex for each year. The start occurs when westerlies persist for at least 10 consecutive days. The end of the vortex, or final warming (FW), occurs on the last date when the winds reverse and do not return to westerly for more than 10 consecutive days. The FWs at $60^{\circ} \mathrm{N}$ and $10 \mathrm{hPa}$ detected with this method agree reasonably well with previously published FW dates, such as from $\mathrm{Hu}$ et al. (2014) (see Table S1 in the supplemental material), while maintaining consistency with the major SSW definition.

SSWs are then detected by reversals during this extended winter season, but with a more stringent requirement that zonal winds must return to westerlies for 30 consecutive days between events, including from the final warming. A 20-day separation, however, does not significantly change our results. Table 1 compares our SSW dates based on zonal wind reversal at $60^{\circ}$ latitude and $10 \mathrm{hPa}$ with CP07. Only three events, all in March, are classified as midwinter SSWs by CP07 but not by our method. Two of these dates are not separated from earlier SSW dates by at least 30 consecutive days of westerlies; the other (14 March 1988) does not return to westerlies for at least 30 consecutive days before the final warming (see Fig. S1 in the supplemental material).

Using these separation and final warming criteria, we examine how the dates and synoptic properties of SSWs vary with the latitude and level at which the zonal wind is measured, and with the threshold of deceleration. Here, the "threshold" sets the magnitude to which the vortex winds must decelerate to count as a major event. It has traditionally been defined at $0 \mathrm{~m} \mathrm{~s}^{-1}$ because planetary waves cannot propagate into easterly flow (Charney and Drazin 1961). For event separation, with negative thresholds $\left(u_{c} \leq 0 \mathrm{~m} \mathrm{~s}^{-1}\right)$ the winds must return to westerly $\left(u>0 \mathrm{~m} \mathrm{~s}^{-1}\right)$ for at least 30 consecutive days, whereas with positive thresholds $\left(u_{c}>0 \mathrm{~m} \mathrm{~s}^{-1}\right)$ the winds must exceed $u_{c}$ for at least 30 consecutive days after the event.

The mean of each synoptic property in section 3 is found by averaging over all events determined at a given location and threshold. Significance testing is performed via Monte Carlo sampling, in which we repeatedly sample the same day and month of events for a particular set of parameters but randomize the years 500 times. We then determine if the difference in means between the two distributions (assuming unequal variances) exceeds the 95\% Student's $t$ test. In most cases, the signals are significantly different everywhere. If fewer than two SSWs per decade (i.e., fewer than 12 SSWs from 1958 to 2016) are detected at a given location, the metric is assigned a missing value. 
TABLE 1. Major SSWs in the Northern Hemisphere defined by reversals of the zonal wind at $60^{\circ} \mathrm{N}$ and $10 \mathrm{hPa}$, for (left) this study and (right) CP07. The last row shows the total number of SSWs.

\begin{tabular}{|c|c|}
\hline Major SSWs: This study & Major SSWs: CP07 \\
\hline 30 Jan 1958 & 30 Jan 1958 \\
\hline 17 Jan 1960 & 17 Jan 1960 \\
\hline 30 Jan 1963 & 30 Jan 1963 \\
\hline 18 Dec 1965 & 18 Dec 1965 \\
\hline 23 Feb 1966 & 23 Feb 1966 \\
\hline 7 Jan 1968 & 7 Jan 1968 \\
\hline 29 Nov 1968 & 29 Nov 1968 \\
\hline 2 Jan 1970 & 2 Jan 1970 \\
\hline 18 Jan 1971 & 18 Jan 1971 \\
\hline 20 Mar 1971 & 20 Mar 1971 \\
\hline 31 Jan 1973 & 31 Jan 1973 \\
\hline 9 Jan 1977 & 9 Jan 1977 \\
\hline 22 Feb 1979 & 22 Feb 1979 \\
\hline 29 Feb 1980 & 29 Feb 1980 \\
\hline 6 Feb 1981 & 6 Feb 1981 \\
\hline- & 4 Mar 1981 \\
\hline 4 Dec 1981 & 4 Dec 1981 \\
\hline 24 Feb 1984 & 24 Feb 1984 \\
\hline 1 Jan 1985 & 1 Jan 1985 \\
\hline 23 Jan 1987 & 23 Jan 1987 \\
\hline 8 Dec 1987 & 8 Dec 1987 \\
\hline - & $14 \operatorname{Mar} 1988$ \\
\hline 21 Feb 1989 & 21 Feb 1989 \\
\hline 15 Dec 1998 & 15 Dec 1998 \\
\hline 26 Feb 1999 & 26 Feb 1999 \\
\hline $20 \operatorname{Mar} 2000$ & 20 Mar 2000 \\
\hline 11 Feb 2001 & 11 Feb 2001 \\
\hline 31 Dec 2001 & 31 Dec 2001 \\
\hline 18 Jan 2003 & 18 Jan 2003 \\
\hline 5 Jan 2004 & 5 Jan 2004 \\
\hline 21 Jan 2006 & 21 Jan 2006 \\
\hline 24 Feb 2007 & $24 \mathrm{Feb} 2007$ \\
\hline 22 Feb 2008 & 22 Feb 2008 \\
\hline 24 Jan 2009 & 24 Jan 2009 \\
\hline 9 Feb 2010 & 9 Feb 2010 \\
\hline- & $24 \operatorname{Mar} 2010$ \\
\hline 7 Jan 2013 & 7 Jan 2013 \\
\hline 34 & 37 \\
\hline
\end{tabular}

\section{Optimizing the SSW definition}

CP07 and Charlton et al. (2007) propose several key metrics for evaluating major SSWs in model simulations (cf. Table 3 in CP07). Here, we consider similar properties, but apply them to zonal wind decelerations everywhere between 50 and $1 \mathrm{hPa}, 50^{\circ}-80^{\circ} \mathrm{N}$, and for thresholds from -10 to $10 \mathrm{~m} \mathrm{~s}^{-1}$.

The frequency of SSW events is quite sensitive to where the zonal wind deceleration is defined (Fig. 1; see also Butler et al. 2015). At levels below $\sim 10 \mathrm{hPa}$, the number of zonal wind reversals per decade increases primarily with latitude; at levels above $10 \mathrm{hPa}$, the frequency is primarily a function of height (Fig. 1a). Note that regions that have similar SSW frequency are not necessarily detecting the same events. Figure $1 \mathrm{c}$ shows the percent match ${ }^{1}$ of events within \pm 10 days of CP07 SSW events (i.e., reversals at $10 \mathrm{hPa}$ and $60^{\circ} \mathrm{N}$ ). Zonal wind reversals along the edge of the polar vortex detect greater than $50 \%$ of the same events (solid black contour), although similarities greater than $80 \%$ are uncommon.

At $10 \mathrm{hPa}$, the frequency of SSW events decreases if the threshold value is more negative, particularly equatorward of $65^{\circ} \mathrm{N}$ (Fig. 1b). While more events are detected as the critical threshold is relaxed to more positive values, these events also have weaker dynamic impacts overall (Figs. 2 and 3). The agreement of dates with those at $0 \mathrm{~m} \mathrm{~s}^{-1}$ and $10 \mathrm{hPa}$ and $60^{\circ} \mathrm{N}$ is greater than $50 \%$ for a broad range of different thresholds; in particular, as the required threshold becomes more negative, one needs to use decelerations at more poleward locations to detect the same events.

Figure 2 shows how two fundamental synoptic characteristics of SSWs, the suddenness of the vortex breakdown and the magnitude of the temperature increase, vary depending on the location and threshold of the deceleration. "Suddenness" is characterized by the change in the $60^{\circ}-80^{\circ} \mathrm{N}$ zonal-mean zonal wind, massweighted and vertically averaged from 50 to $1 \mathrm{hPa}$, computed from the mean of days 0-5 after the event minus days 5-15 prior to each event (Figs. 2a,b). While the vortex must decelerate in all cases to trigger an event, larger values here indicate that the deceleration was more rapid. For example, at $60^{\circ} \mathrm{N}$ and $10 \mathrm{hPa}$ (Fig. 2a, black dot), the value is $-12.2 \mathrm{~m} \mathrm{~s}^{-1}$ : this indicates that, for events defined by a reversal at this location (as in CP07), the entire vortex abruptly slows by $\sim 12 \mathrm{~m} \mathrm{~s}^{-1}$ in approximately 10 days. (Note that the winds at a particular location may decelerate far more than the latitudinally and vertically averaged vortex; e.g., the net change in zonal wind at $60^{\circ} \mathrm{N}$ and $10 \mathrm{hPa}$ is approximately $-30 \mathrm{~m} \mathrm{~s}^{-1}$ for reversals occurring there.) If one defines events by a reversal at $70^{\circ} \mathrm{N}$ and $5 \mathrm{hPa}$, the average deceleration is weaker, approximately $-10.6 \mathrm{~m} \mathrm{~s}^{-1}$. Overall, we find that the most abrupt events are found when the zonal wind reverses near the climatological maximum of the polar jet in the midstratosphere, from 30 to $5 \mathrm{hPa}$ as one moves from $\sim 60^{\circ}$ to $72^{\circ} \mathrm{N}$. Figure $2 \mathrm{~b}$ shows that if we fix the pressure level at which events are defined at $10 \mathrm{hPa}$, requiring a stronger threshold (i.e., less

\footnotetext{
${ }^{1}$ Percent match is calculated here as $P=A / N \times 100$, where $A$ is the number of same events detected at both $10 \mathrm{hPa}$ and $60^{\circ} \mathrm{N}$ and a particular location, and $N=A+B+C$, where $B$ is the number of events detected at $10 \mathrm{hPa}$ and $60^{\circ} \mathrm{N}$ but not the other location, and $C$ is the number of events detected at the particular location but not at $10 \mathrm{hPa}$ and $60^{\circ} \mathrm{N}$.
} 

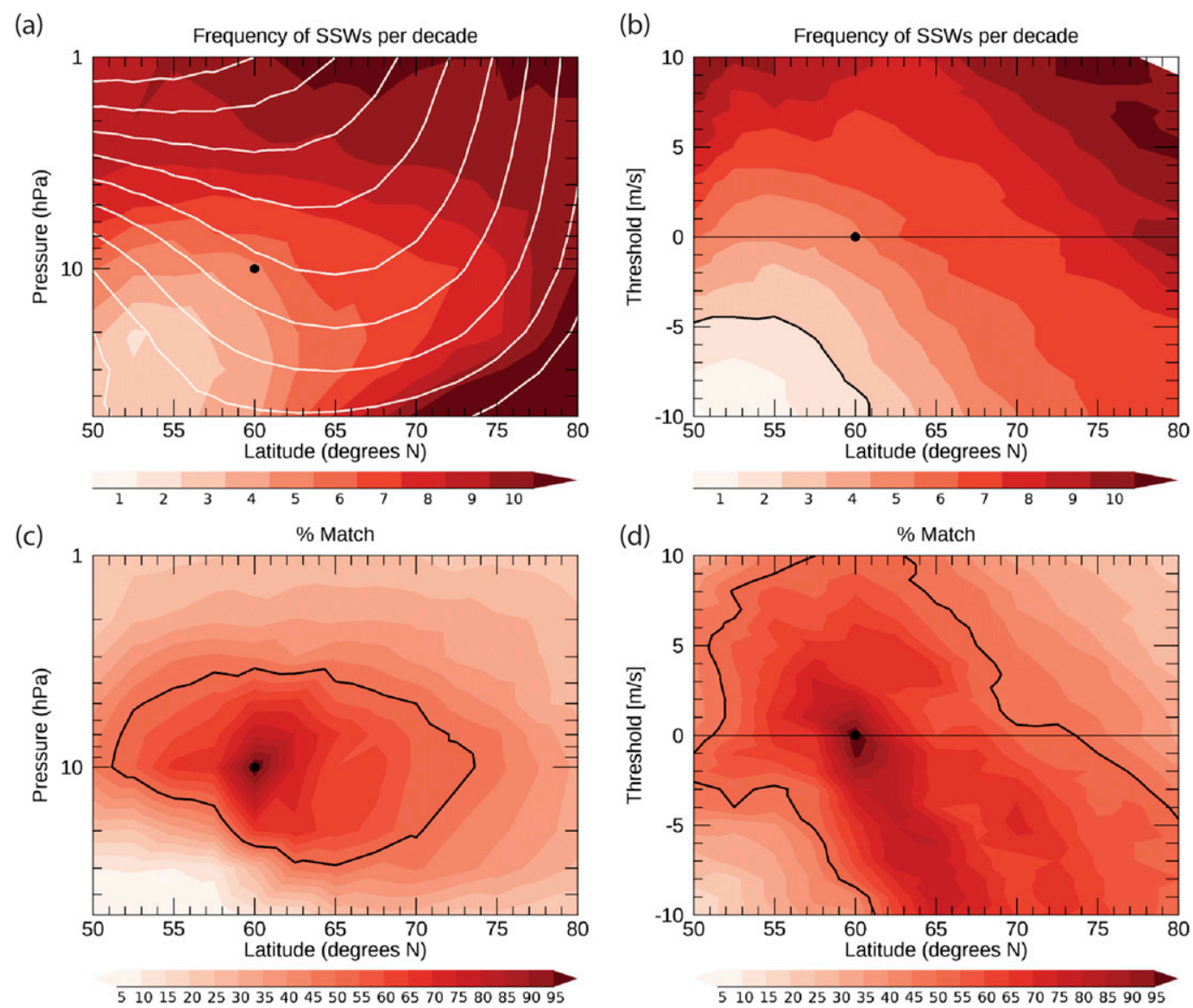

FIG. 1. (a),(b) The frequency or number of SSWs per decade and (c),(d) the percent match of SSW dates at a given location with SSW dates at $60^{\circ} \mathrm{N}, 10 \mathrm{hPa}$, and a $0 \mathrm{~m} \mathrm{~s}^{-1}$ threshold. Thin white contours in (a) show the mean DJFM zonal winds at $3 \mathrm{~m} \mathrm{~s}^{-1}$ intervals, with the highest contour near $50^{\circ}-60^{\circ} \mathrm{N}$ at $1 \mathrm{hPa}$ equal to $39 \mathrm{~m} \mathrm{~s}^{-1}$. The black contour in (b) indicates where there are fewer than two SSWs per decade; black contours in (c) and (d) indicate where date agreement is higher than $50 \%$.

than $-2 \mathrm{~m} \mathrm{~s}^{-1}$ ) selects events with greater deceleration or suddenness. This is partly by construction; a negative threshold will capture fewer, stronger events.

The "warming" metric (Figs. 2c,d) is defined as the polar cap $\left(50^{\circ}-90^{\circ} \mathrm{N}\right)$ temperature anomaly, mass-weighted and vertically averaged from 50 to $1 \mathrm{hPa}$, for the mean from day -5 to +5 around each event. It is maximized for zonal wind reversals that occur on the equatorward edge of the polar vortex $\left(50^{\circ}-65^{\circ} \mathrm{N}\right)$, from 20 to $5 \mathrm{hPa}$. As before, requiring a more negative threshold at $10 \mathrm{hPa}$ (Fig. 2d) selects events with larger temperature increases. Note, however, that for events at $60^{\circ} \mathrm{N}$ with thresholds near from +1 to $3 \mathrm{~m} \mathrm{~s}^{-1}$, both the suddenness and the temperature increase have magnitudes similar to those of events with thresholds from 0 to $-3 \mathrm{~m} \mathrm{~s}^{-1}$. This similarity suggests that wind decelerations that nearly reach $0 \mathrm{~ms}^{-1}$, but do not actually reverse the polar vortex, are still associated with substantial dynamic changes in the stratosphere.
Figure 3 considers two additional desirable properties of major SSWs: upward and downward coupling between the troposphere and the stratosphere. Upward wave propagation from the troposphere is represented by the $45^{\circ}-75^{\circ} \mathrm{N}$ eddy heat flux $\left(v^{\prime} T^{\prime}\right)$ anomalies at $100 \mathrm{hPa}$, averaged from days -20 to 0 of each event (Fig. 3a). Reversals occurring equatorward of $65^{\circ} \mathrm{N}$ and at levels below $10 \mathrm{hPa}$ are associated with stronger poleward (positive) eddy heat flux anomalies prior to the event, indicating that stronger wave driving is necessary to reverse the zonal wind here. Note that there are also fewer reversals that occur here (Fig. 1). Stronger heat flux anomalies are also associated with decelerations below the $0 \mathrm{~m} \mathrm{~s}^{-1}$ threshold at $10 \mathrm{hPa}$ (Fig. 3b).

The strength of the stratospheric coupling to the surface is characterized by the mean Arctic Oscillation index for days 0-60 after events (Figs. 3c,d). The AO is the dominant mode of climate variability in the $\mathrm{NH}$ 
(a)
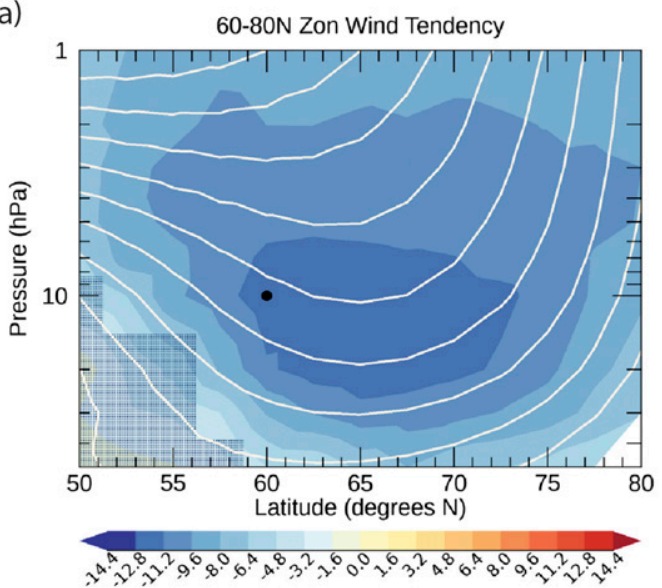

(c)

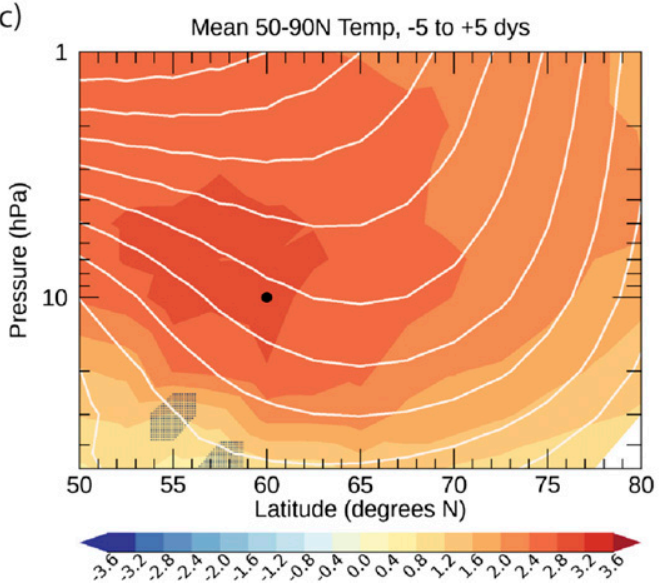

(b)
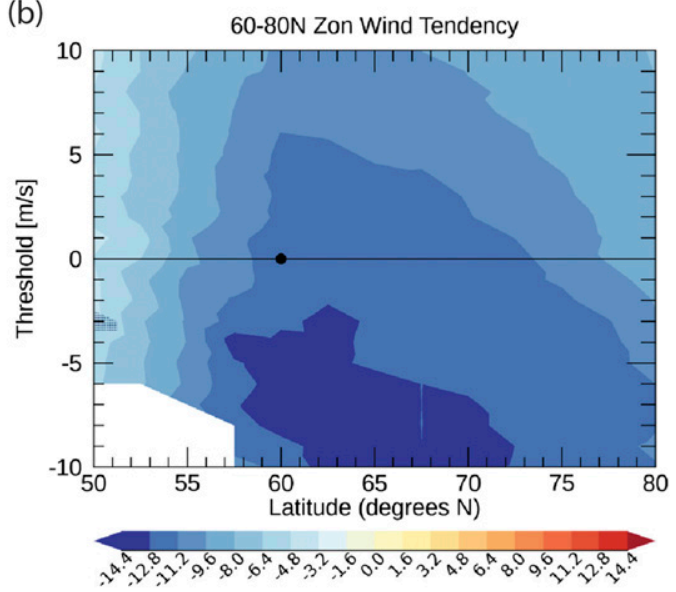

(d)

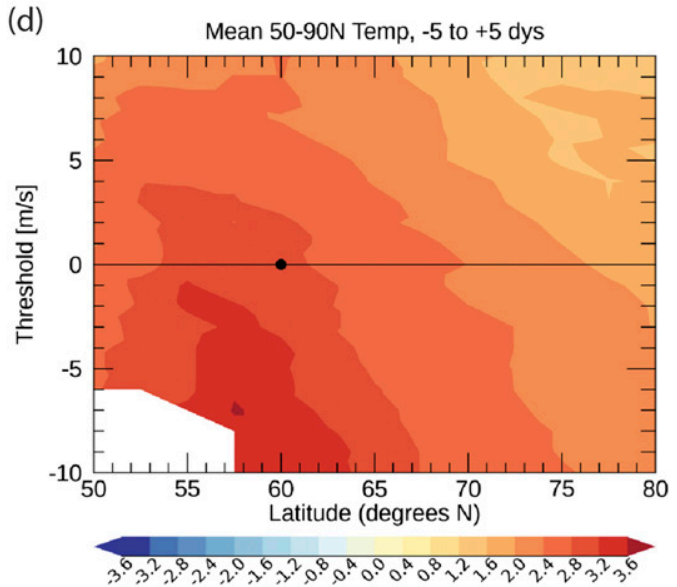

FIG. 2. (a),(b) The mean zonal wind change $\left(\mathrm{m} \mathrm{s}^{-1}\right)$ averaged from $60^{\circ}-80^{\circ} \mathrm{N}$ and $50-1 \mathrm{hPa}$ for days $0-5$ after each reversal minus days 5-15 prior to each reversal, and (c),(d) the mean temperature anomaly (K) averaged from $50^{\circ}$ to $90^{\circ} \mathrm{N}$ and 50 to $1 \mathrm{hPa}$ for days -5 to +5 of each reversal, as a function of latitude and (a), (c) pressure level (with a threshold of $0 \mathrm{~m} \mathrm{~s}^{-1}$ ) and (b),(d) threshold (at $10 \mathrm{hPa}$ ). Thin white contours in (a) and (c) are as in Fig. 1. Stippling indicates where values are not significant based on a 95\% Student's $t$ test (see details in section 2).

midlatitudes; a weakening of the polar vortex is associated with the negative phase of the AO (i.e., an equatorward shift of the tropospheric storm track). It is clear that reversals in the lower stratosphere between $\sim 60^{\circ}$ and $70^{\circ} \mathrm{N}$ result in the largest impacts on the AO (Fig. 3c), in agreement with previous studies (Gerber et al. 2009; Hitchcock and Simpson 2014; Maycock and Hitchcock 2015; Karpechko et al. 2017). Similar results are found for a metric based on Eurasian surface temperature anomalies (not shown). For decelerations at $10 \mathrm{hPa}$ (Fig. 3d), AO impacts are not strongly dependent on threshold, although the largest changes occur for negative thresholds between $\sim 62^{\circ}$ and $72^{\circ} \mathrm{N}$. Comparing the top and bottom rows of Fig. 3, it is seen that wind decelerations with the strongest upward wave driving are not always associated with the strongest influence on the surface.

\section{Discussion and conclusions}

To summarize these findings, we create a qualitative "score" ranging from 0 to 1 for each of the four key SSW properties (Figs. 2 and 3) by dividing the value of each property at a particular location/threshold by the maximum value observed over all locations/thresholds. A score of 1 then implies the optimal location for a given property. Figure 4 shows the average scores, giving equal weight to each property. While it is somewhat arbitrary to equally weight each property, the scores are not heavily dominated by any one metric. We find that the key properties for SSWs are maximized (average scores $>0.8$ ) for reversals between $55^{\circ}$ and $70^{\circ} \mathrm{N}$ (slightly equatorward of the polar vortex climatological maximum) in the midstratosphere from 30 to $5 \mathrm{hPa}$ (Fig. 4a), and for decelerations near or below $0 \mathrm{~m} \mathrm{~s}^{-1}$ (Fig. 4b). 

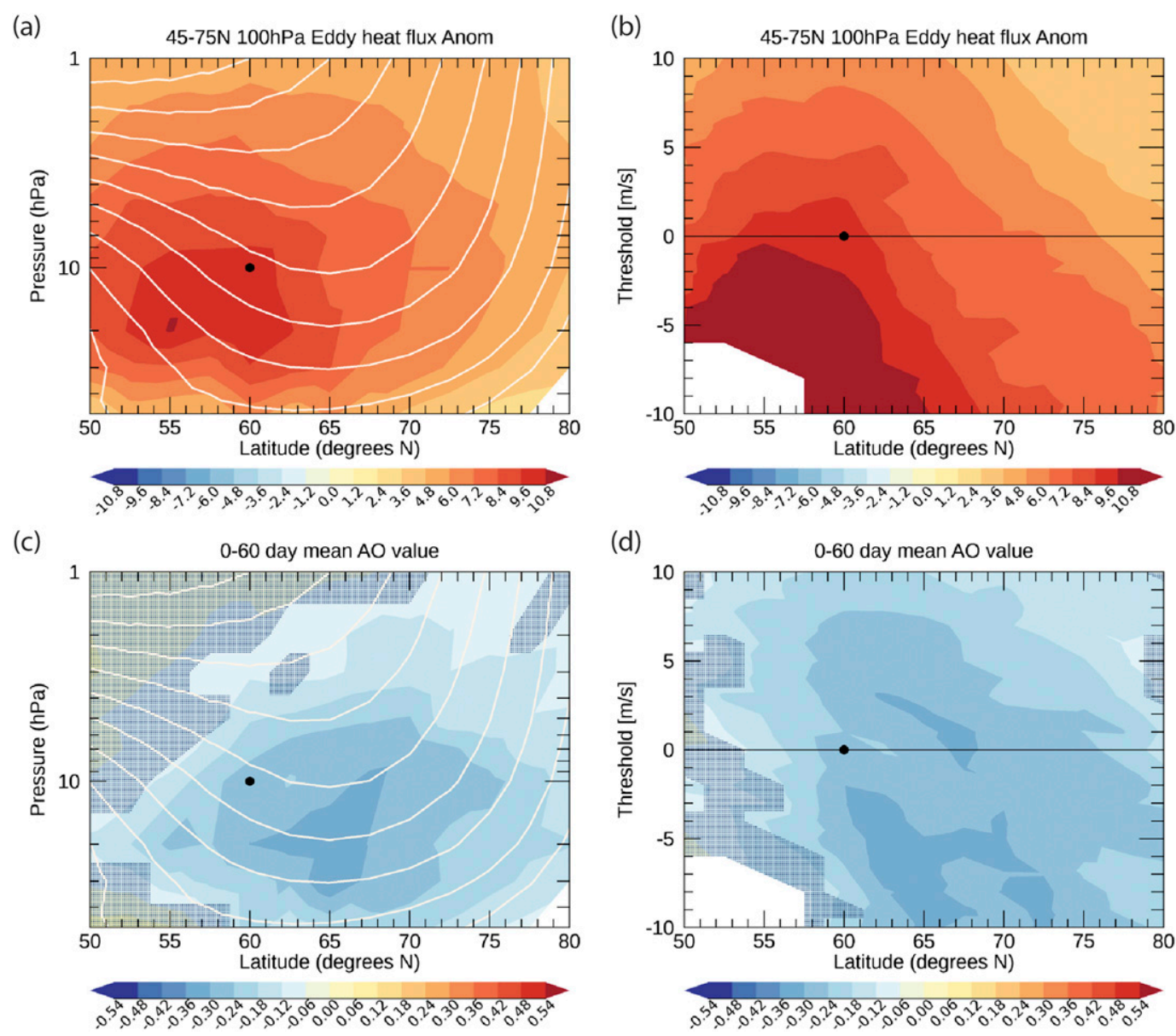

FIG. 3. (a),(b) The mean eddy heat flux anomaly $\left(\mathrm{K} \mathrm{m} \mathrm{s}^{-1}\right)$ at $100 \mathrm{hPa}$ and $45^{\circ}-75^{\circ} \mathrm{N}$ for days $20-0$ prior to each reversal, and (c),(d) the mean daily Arctic Oscillation index (standardized by the DJFM mean) for days 0-60 after each reversal, as a function of latitude and (a),(c) pressure level (with a threshold of $0 \mathrm{~m} \mathrm{~s}^{-1}$ ) and (b),(d) threshold $($ at $10 \mathrm{hPa})$. Thin white contours in (a) and (c) are as in Fig. 1. Stippling indicates where values are not significant based on a $95 \%$ Student's $t$ test (see details in section 2).

Removing one of these metrics (or modifying their details) does not qualitatively change this result, although the AO metric tends to depress the scores for events characterized at upper levels.

There is a fairly narrow range of pressure levels, latitudes, and thresholds where features relevant to major SSWs are maximized, and for which there are still a reasonable number of events. Zonal wind reversals at $10 \mathrm{hPa}$ and $60^{\circ} \mathrm{N}$ fall within this region, indicating that the historically used definition does detect SSWs with a strong dynamic response in the stratosphere and strong coupling to the troposphere; this is a testament to the synoptic intuition of meteorologists in the presatellite era. Our results also suggest that while zonal wind decelerations near $0 \mathrm{~m} \mathrm{~s}^{-1}$ have similar impacts to true wind reversals, there is a decline in stratospheric and tropospheric impacts as the threshold is relaxed to more positive values.
The optimization could be extended to cover more parameters (e.g., the separation criteria) and metrics (e.g., the surface temperature response), but sampling uncertainty associated with the finite reanalysis record and the continuum nature of stratospheric variability means that defining SSWs will always involve some degree of subjectivity (e.g., Coughlin and Gray 2009). Further analysis is also needed to determine how these results apply to model simulations with mean state biases (e.g., Kim et al. 2017).

There are recent and ongoing efforts to reevaluate and improve the standard definition for SSWs as defined by the WMO (Butler et al. 2014; Butler et al. 2015). While our analysis lends evidence that major changes to the current definition are unwarranted, there are still potential avenues for improvement. These include clarity of the separation criteria and the inclusion of 
(a)

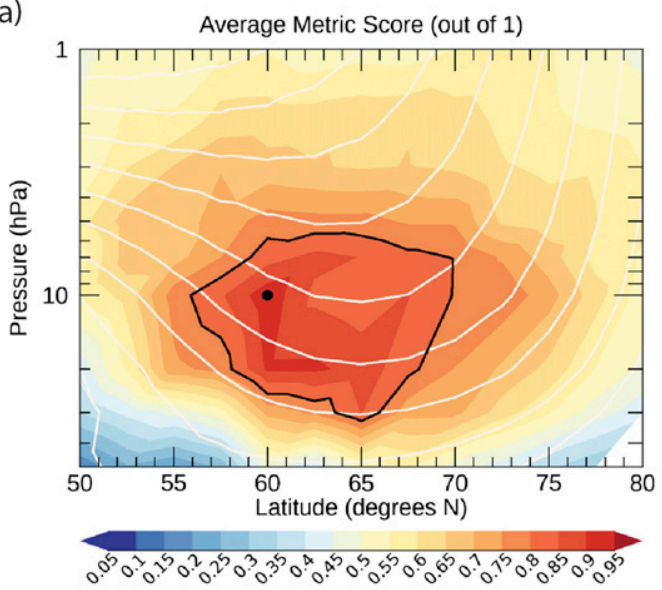

(b)

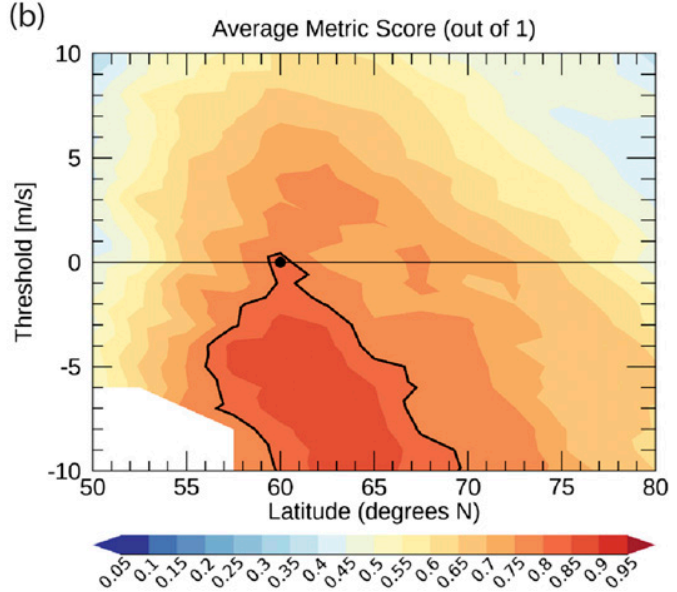

FIG. 4. The average of all the metric scores, defined as the metric at each location divided by the maximum metric, as a function of latitude and (a) pressure level (with a threshold of $0 \mathrm{~m} \mathrm{~s}^{-1}$ ) and (b) threshold (at $10 \mathrm{hPa}$ ). Thin white contours in (a) and (c) are as in Fig. 1. Solid black line indicates where the metric score exceeds 0.8.

minor and final warmings consistent with the major warming definition.

Acknowledgments. We thank three anonymous reviewers for their feedback on an earlier draft of the manuscript. EPG was supported by the U.S. National Science Foundation (AGS-1546585).

\section{REFERENCES}

Baldwin, M. P., 2001: Annular modes in global daily surface pressure. Geophys. Res. Lett., 28, 4115-4118, https://doi.org/ 10.1029/2001GL013564.

, and D. W. J. Thompson, 2009: A critical comparison of stratosphere-troposphere coupling indices. Quart. J. Roy. Meteor. Soc., 135, 1661-1672, https://doi.org/10.1002/qj.479.

Blume, C., K. Matthes, and I. Horenko, 2012: Supervised learning approaches to classify sudden stratospheric warming events. J. Atmos. Sci., 69, 1824-1840, https://doi.org/ 10.1175/JAS-D-11-0194.1.

Butler, A. H., E. P. Gerber, D. Mitchell, and W. J. M. Seviour, 2014: New efforts in developing a standard definition for sudden stratospheric warmings. SPARC Newsletter, No. 43, ETH Zurich, Zurich, Switzerland, 23-24, http://www.sparc-climate.org/ publications/newsletter/.

- D. J. Seidel, S. C. Hardiman, N. Butchart, T. Birner, and A. Match, 2015: Defining sudden stratospheric warmings. Bull. Amer. Meteor Soc., 96, 1913-1928, https://doi.org/10.1175/BAMS-D-13-00173.1.

Charlton, A. J., and L. M. Polvani, 2007: A new look at stratospheric sudden warmings. Part I: Climatology and modeling benchmarks. J. Climate, 20, 449-469, https://doi.org/10.1175/JCLI3996.1.

- and Coauthors, 2007: A new look at stratospheric sudden warmings. Part II: Evaluation of numerical model simulations. J. Climate, 20, 470-488, https://doi.org/10.1175/JCLI3994.1.

Charney, J. G., and P. G. Drazin, 1961: Propagation of planetary-scale disturbances from the lower into the upper atmosphere. J. Geophys. Res., 66, 83-109, https://doi.org/ 10.1029/JZ066i001p00083.
Coughlin, K., and L. J. Gray, 2009: A continuum of sudden stratospheric warmings. J. Atmos. Sci., 66, 531-540, https:// doi.org/10.1175/2008JAS2792.1.

Ebita, A., and Coauthors, 2011: The Japanese 55-year Reanalysis "JRA-55": An interim report. Sci. Online Lett. Atmos., 7, 149152, https://doi.org/10.2151/sola.2011-038.

Gerber, E. P., C. Orbe, and L. M. Polvani, 2009: Stratospheric influence on the tropospheric circulation revealed by idealized ensemble forecasts. Geophys. Res. Lett., 36, L24801, https:// doi.org/10.1029/2009GL040913.

— , and Coauthors, 2010: Stratosphere-troposphere coupling and annular mode variability in chemistry-climate models. J. Geophys. Res., 115, D00M06, https://doi.org/10.1029/2009JD013770.

Hannachi, A., D. Mitchell, L. Gray, and A. Charlton-Perez, 2011: On the use of geometric moments to examine the continuum of sudden stratospheric warmings. J. Atmos. Sci., 68, 657-674, https://doi.org/10.1175/2010JAS3585.1.

Hitchcock, P., and I. R. Simpson, 2014: The downward influence of stratospheric sudden warmings. J. Atmos. Sci., 71, 3856-3876, https://doi.org/10.1175/JAS-D-14-0012.1.

- T. G. Shepherd, and G. L. Manney, 2013: Statistical characterization of Arctic polar-night jet oscillation events. J. Climate, 26, 2096-2116, https://doi.org/10.1175/JCLI-D-12-00202.1.

$\mathrm{Hu}$, J., R. Ren, and H. Xu, 2014: Occurrence of winter stratospheric sudden warming events and the seasonal timing of spring stratospheric final warming. J. Atmos. Sci., 71, 2319-2334, https://doi.org/10.1175/JAS-D-13-0349.1.

Karpechko, A. Y., P. Hitchcock, D. H. W. Peters, and A. Schneidereit, 2017: Predictability of downward propagation of major sudden stratospheric warmings. Quart. J. Roy. Meteor. Soc., 143, 1459-1470, https://doi.org/10.1002/qj.3017.

Kim, J., S.-W. Son, E. P. Gerber, and H.-S. Park, 2017: Defining sudden stratospheric warming in climate models: Accounting for biases in model climatologies. J. Climate, 30, 5529-5546, https://doi.org/10.1175/JCLI-D-16-0465.1.

Labitzke, K., 1981: Stratospheric-mesospheric midwinter disturbancesA summary of observed characteristics. J. Geophys. Res., 86, 9665-9678, https://doi.org/10.1029/JC086iC10p09665.

Maury, P., C. Claud, E. Manzini, A. Hauchecorne, and P. Keckhut, 2016: Characteristics of stratospheric warming events during 
northern winter. J. Geophys. Res. Atmos., 121, 5368-5380, https:// doi.org/10.1002/2015JD024226.

Maycock, A. C., and P. Hitchcock, 2015: Do split and displacement sudden stratospheric warmings have different annular mode signatures? Geophys. Res. Lett., 42, $10943-10$ 951, https:// doi.org/10.1002/2015GL066754.

McInturff, R. M., Ed., 1978: Stratospheric warmings: Synoptic, dynamic and general-circulation aspects. Tech. Rep. NASA-RP1017, 166 pp., https://ntrs.nasa.gov/archive/nasa/casi.ntrs.nasa.gov/ 19780010687.pdf.

Mitchell, D. M., L. J. Gray, and J. Charlton-Perez, 2011: The structure and evolution of the stratospheric vortex in response to natural forcings. J. Geophys. Res., 116, D15110, https:// doi.org/10.1029/2011JD015788.

Oort, A. H., and H. Liu, 1993: Upper-air temperature trends over the globe, 1958-1989. J. Climate, 6, 292-307, https://doi.org/ 10.1175/1520-0442(1993)006<0292:UATTOT>2.0.CO;2.

Palmeiro, F. M., D. Barriopedro, R. García-Herrera, and N. Calvo, 2015: Comparing sudden stratospheric warming definitions in reanalysis data. J. Climate, 28, 6823-6840, https://doi.org/ 10.1175/JCLI-D-15-0004.1.
Quiroz, R. S., A. J. Miller, and R. M. Nagatani, 1975: A comparison of observed and simulated properties of sudden stratospheric warmings. J. Atmos. Sci., 32, 1723-1736, https://doi.org/ 10.1175/1520-0469(1975)032<1723:ACOOAS > 2.0.CO;2.

Scherhag, R., 1952: Die explosionsartigen Stratosparenerwarmungen des Spatwinters 1952. Ber. Det. Wetterdienstes, 38, 51-63.

Seviour, W. J. M., D. M. Mitchell, and L. J. Gray, 2013: A practical method to identify displaced and split stratospheric polar vortex events. Geophys. Res. Lett., 40, 5268-5273, https://doi.org/ 10.1002/grl.50927.

Waugh, D. W., and W. J. Randel, 1999: Climatology of Arctic and Antarctic polar vortices using elliptical diagnostics. J. Atmos. Sci., 56, 1594-1613, https://doi.org/10.1175/1520-0469(1999)056<1594: COAAAP $>2.0 . \mathrm{CO} ; 2$.

WMO CAS, 1978: WMO Commission for Atmospheric Sciences: Abridged Final Report of the Seventh Session, Manila, 27 February-10 March 1978. WMO-No. 509, 113 pp., http:// library.wmo.int/pmb_ged/wmo_509_en.pdf.

WMO/IQSY, 1964: International Years of the Quiet Sun (IQSY) 1964-65. Alert messages with special references to stratwarms. WMO/IQSY Rep. 6, 19 pp. 